\title{
(152)
}

\section{Inducement of Agarwood Resin Formation in Gyrinops walla Using Actinomycetes Species}

\author{
H.I.D. Hitihamu ${ }^{1 *}$, S.M.C.U.P. Subasinghe ${ }^{1}$, K.M.E.P. Fernando ${ }^{2}$ \\ ${ }^{1}$ Department of Forestry and Environmental Science, University of Sri Jayewardenepura, Sri Lanka \\ ${ }^{2}$ Department of Botany, University of Sri Jayewardenepura, Sri Lanka \\ *imalkahitihamu@gmail.com
}

\begin{abstract}
Gyrinops walla Gaertn is the only agarwood forming species naturally growing in Sri Lanka. This species, belongs to the family Thymalaeaceae is commonly growing in the low country wet zone of Sri Lanka where the annual rainfall is high. Being very valuable due to the pleasant aroma, agarwood resin is extensively used in cosmetic manufacturing, cultural and religious activities. It is produced as a result of a self-defense mechanism towards any stress caused by several factors which can be physical, chemical and biological. However, use of fungal species to artificially induce agarwood resin formation in Aquilaria species is common in the Southeast Asian region. The present study aimed to explore the possibility of inducing agarwood formation in $G$. walla trees using Actinomycetes species.
\end{abstract}

Actinomycetes species were isolated from fresh agarwood resinous tissues of G. walla and associated soils by culturing them in the laboratory. In order to do that, the Actinomycetes species growing with other fungal species in the culture plates were identified using their colony characteristics, reproductive structures and then pure cultures were prepared. Two $g$ of Actinomycetes with solid agar medium was inoculated into non-agarwood formed G. walla trees under aseptic conditions. Observations were made for the agarwood resins in the stem tissues at $10 \mathrm{~cm}$ intervals above and below the inoculated points at monthly intervals. Discolouration of the stem tissues was recorded in the field. Resin contents (w/w\%) were determined by solvent extraction and the constituents were analysed using GC-MS technique. Stem tissue discolouration varying from yellow to black was observed form the first month after the inoculation. Resin contents varied from $0.03 \%$ to $1.66 \%$ and high resin contents were observed in dark coloured tissues usually extracted closer to the inoculation points. Moreover, 12 constituents were identified which were also common to the agarwood resins extracted from the Aquilaria species. This study is the first attempt in Sri Lanka investigating the potential of Actinomycetes species as inducing agents of agarwood formation and results reveal that Actinomycetes species are effective microorganisms in production or agarwood resins in G. walla

Keywords: Gyrinops walla, Agarwood, Actinomycetes, Thymalaeaceae 